\title{
Publisher Correction: Structural insights into chaperone addiction of toxin-antitoxin systems
}

\author{
Valérie Guillet', Patricia Bordes², Cécile Bon ${ }^{1}$, Julien Marcoux (10 1, Virginie Gervais ${ }^{1}$, Ambre Julie Sala², \\ Suzana Dos Reis ${ }^{1}$, Nawel Slama², Israel Mares-Mejía', Anne-Marie Cirinesi², Laurent Maveyraud (i) ${ }^{1}$, \\ Pierre Genevaux ${ }^{2} \&$ Lionel Mourey (i) ${ }^{1}$
}

Correction to: Nature Communications; https://doi.org/10.1038/s41467-019-08747-4; published online 15 February 2019

The original version of this Article contained errors in Figures 1 and 4 . In Fig. $1 \mathrm{~b}$, the $M t b-S e c B^{\mathrm{TA}}$ sequence was displayed incorrectly. In the inset panel within Fig. 4c, the $y$-axis of the graph incorrectly read $\left(Q . R_{\mathrm{g}}\right)^{2} \times I(Q) / /(0)$, and should have read $\left(Q \cdot R_{\mathrm{g}}\right)^{2} \times I(Q) / I(0)$. These errors have been corrected in both the PDF and HTML versions of the Article.

Published online: 07 March 2019

\begin{abstract}
(c) Open Access This article is licensed under a Creative Commons Attribution 4.0 International License, which permits use, sharing, adaptation, distribution and reproduction in any medium or format, as long as you give appropriate credit to the original author(s) and the source, provide a link to the Creative Commons license, and indicate if changes were made. The images or other third party material in this article are included in the article's Creative Commons license, unless indicated otherwise in a credit line to the material. If material is not included in the article's Creative Commons license and your intended use is not permitted by statutory regulation or exceeds the permitted use, you will need to obtain permission directly from the copyright holder. To view a copy of this license, visit http://creativecommons.org/licenses/by/4.0/.
\end{abstract}

(C) The Author(s) 2019

\footnotetext{
${ }^{1}$ Institut de Pharmacologie et de Biologie Structurale, IPBS, Université de Toulouse, CNRS, UPS, 31077 Toulouse, France. ${ }^{2}$ Laboratoire de Microbiologie et de Génétique Moléculaires, Centre de Biologie Intégrative (CBI), Université de Toulouse, CNRS, UPS, 31062 Toulouse, France. Correspondence and requests for materials should be addressed to P.G. (email: pierre.genevaux@ibcg.biotoul.fr) or to L.M. (email: lionel.mourey@ipbs.fr)
} 